\title{
REGULAR ARTICLE \\ What are markets? Selected market theories under genuine uncertainty in comparison
}

\author{
Ute Schmiel ${ }^{1}$ (D) $\cdot$ Hendrik Sander $^{1}$
}

Accepted: 10 March 2021 / Published online: 27 April 2021

(c) The Author(s) 2021

\begin{abstract}
Since market economies are the dominant form of regulating economic action all over the world, the question arises how markets are conceived theoretically. Answering this is relevant because we need to know how existing and hypothetical markets work in general, what they "can do", and how one can improve the market order. There are three different market approaches that consider genuine uncertainty. According to the new institutional economics approach, markets are institutions that increase boundedly rational actors' utility. The markets-as-institutional-arrangements approach denies that markets maximize or minimize market outcomes and argues that they enable harmony between individual and common interests. According to the political-cultural approach, markets are political arenas with conflicts between the relevant actors. Deciding reasonably for a theory requires answering whether one theory is more adequate than another. Since literature has not answered this so far, the present paper deals with this issue from a critical-rationalist perspective. It finds that the institutional economics approach is not adequate because its assumptions contradict reality and each other. In contrast, the markets-as-institutional-arrangements approach and the political-cultural approach fulfill critical-rationalist requirements. Therefore, the paper compares them and finds that there are reasons to prefer the political-cultural approach and to interpret the markets-as-institutional-arrangements approach as its special case. Referring to the political-cultural approach has different consequences for analyzing and improving the market order. Taking a political-cultural view implies, e.g., not only focusing on desirable social values and market rules but also on the relevance of interpretative frameworks and power.
\end{abstract}

Keywords Genuine uncertainty · Markets-as-institutional-arrangements approach · Market theories $\cdot$ New institutional economics $\cdot$ Political-cultural approach

JEL classification A11 $\cdot$ B41 $\cdot$ B52 $\cdot$ D49 $\cdot$ D72

Ute Schmiel

Ute.Schmiel@uni-due.de

1 Faculty of Business Administration and Economics, University of Duisburg-Essen, 45127 Essen, Germany 


\section{Introduction}

All over the world, market economies are the dominant form of regulating economic action and we can find great confidence in the abilities of markets (Chang 2011). The OECD, for example, highlights the advantages of (open) markets and argues: "Trade and market openness has [sic!] historically gone hand-in-hand with better economic performance in countries at all levels of development, creating new opportunities for workers, consumers and firms around the globe and helping to lift millions out of poverty. Relatively open economies grow faster than relatively closed ones, and salaries and working conditions are generally better in companies that trade than in those that do not. More prosperity and opportunity around the world also helps [sic!] promote greater stability and security for everyone." (OECD 2020). Due to the relevance of markets, the question arises what markets are. Obviously, if we accept that perception is theory-laden (Popper 1968), the question "What are markets?" is incorrect. More precisely, the question should be how markets are conceived theoretically because the interpretation of markets depends on market theories. Answering the question how markets are conceived theoretically is relevant because we need to know how they work in general, independent of the goods or services that are the subject of exchange, what they "can do", and how one can improve the market order.

From an evolutionary perspective (Witt 2008), market theories can only be adequate if they consider genuine uncertainty as a necessary condition. Genuine uncertainty, sometimes called fundamental uncertainty (Beckert 2013) or radical uncertainty (Kay and King 2020), means that in the choices of actors, potential future environmental conditions can occur that can crucially influence the actors' benefits but are as yet unknown (Buchanan and Vanberg 1991). The first reason for this incomplete knowledge is that individuals cannot inform themselves about all action alternatives. The second reason is that the number of possible environmental conditions and action alternatives is undetermined (Beckert 1996, 2013; Witt 2009; Schubert 2012). In contrast to stochastic uncertainty, genuine uncertainty does not only imply "that we do not know what will happen", but also that we "often do not even know the kinds of things that might happen" (Kay and King 2020, 14). The latter results, e.g., from the fact that individuals learn and influence the future by their decisions (Witt 2003; Dosi et al. 2005), from unforeseeable interaction effects, or from unpredictable innovations and other actors' choices (Beckert 2013).

We can basically find three different strands of market theories under genuine uncertainty. According to a first economic strand, markets are institutions that, compared to perfect markets, only relatively maximize utility or relatively minimize costs. In other words, markets can increase actors' utility. This strand is represented by the new institutional economics. This approach defines a market as "a social network consisting of (i) a set of actors who maintain customer relationships with each other and (ii) an order or governance structure governing the transactions between individual actors. Their common goal is to lower the costs of exchange and thus to reach a higher level of individual utility. Actors have imperfect foresight and are only boundedly rational" (Furubotn and Richter 2005, 350). A second strand of market theories takes a so-called nonteleological view according to which markets cannot maximize or minimize market outcomes (e.g., utility or costs), but still follows 
the (also widespread) belief that markets enable harmony. In this manner, Vanberg argues that markets are institutional arrangements "that may be more or less suitable for allowing individuals to realize mutual gains" (Vanberg 2005, 34). Although the markets-as-institutional-arrangements approach denies that markets maximize or minimize anything (Buchanan and Vanberg 1991), it highlights that markets in general (not necessarily existing markets) enable harmony between individual and common interests. In contrast, the third strand of market theories denies both ideas; that markets maximize or minimize market outcomes or that they enable harmony. According to the approach of this third strand, the political-cultural approach (Fligstein 1996; 2001), markets are not only institutional arrangements but also social and political arenas with conflicts between their relevant actors. The following Fig. 1 shows the different market approaches:

Because of their differences, the question arises how to deal with these diverse theories. In particular, the question is if one theory is more adequate than the others. The comparison and evaluation of these different market theories is necessary to decide reasonably for a theory. However, there are only few comparisons of market theories in the prevailing literature. Vanberg $(2001,2011,2014)$ and Fligstein (2001) compare their approaches especially with the neoclassical market approach. Chang (2014) and Boettke (2012) compare different market theories and economic means-end approaches. Their comparison is, thus, broader than ours since they also deal with economic policy approaches. In contrast, we focus on (explicative) theories and examine whether and how desired values of a market order can actually be realized, but we do not analyze the pros and cons of different market goals (e.g. efficiency). However, neither Chang (2014) nor Boettke (2012) compare the marketsas-institutional-arrangements approach and the political-cultural approach so this comparison is still missing. Moreover, especially Chang does not evaluate different theories but argues that "different approaches to economics can actually benefit a lot from learning from each other, making our understanding of the economic world richer" (Chang 2014, 115). Thus, the diversity of theories should be preserved and promoted. Yet, the core objection of the present paper to this 'anything goes attitude' is that Chang does not have a clear criterion according to which he follows a certain theory. Rather, the decision for or against a market theory is taken arbitrarily.

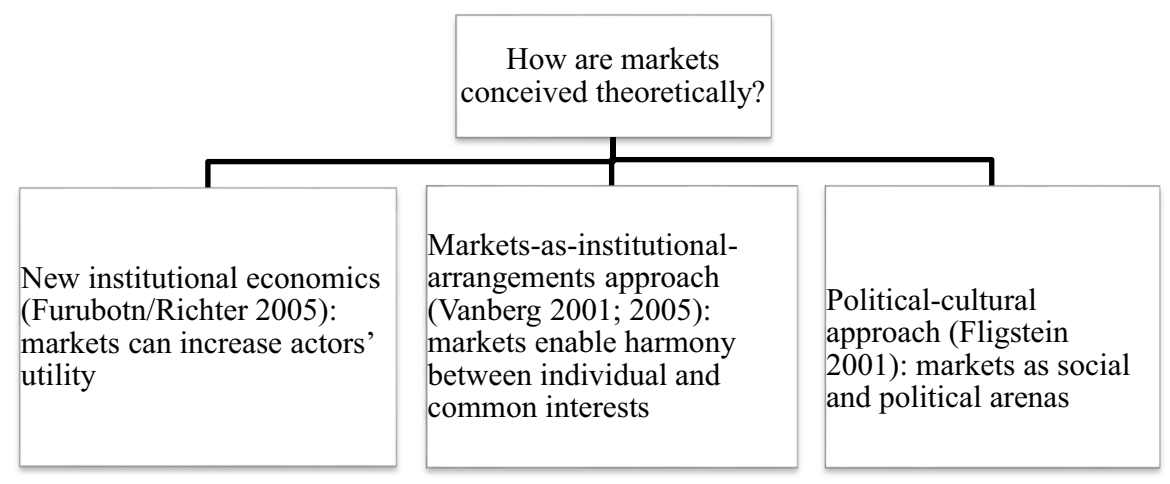

Fig. 1 Market approaches under genuine uncertainty 
In contrast, we follow Lakatos (1970) who argued that a methodology without a criterion to reject any theory means that science is nothing but growing chaos. Therefore, the present paper refers to a critical-rationalist framework. This methodological view evaluates theories regarding different requirements they should fulfill (Albert 1985; Gadenne 2006, 2013).

The present paper analyzes the new institutional economics approach (Furubotn and Richter 2005), the markets-as-institutional-arrangements approach (Vanberg 2001, 2005, 2011), and the political-cultural approach (Fligstein 1996, 2001) because it focuses on market theories that consider genuine uncertainty. We are specifically interested in different theoretical notions of markets rather than in the history of economic thought (for that focus, see, e.g., Boettke and Candela 2017). For that reason, we focus on Weber's ideal types (Ritzer 2008) of existing market theories and neglect, e.g., the fact that scientists may use several theories or combine different theories. Further, we do not provide a thorough survey of market theories under genuine uncertainty. Certainly, from an evolutionary perspective, there are approaches that deal with economic evolution on a micro, meso, and macro level (Potts 2000; Dopfer et al. 2004; Dopfer and Potts 2008; Dopfer 2012; Witt 2008). Yet, whilst their core focus is mechanisms of change, our subject is broader and deals with the question how markets work in general. Another group of theories we do not focus on is the derivative of new institutional economic theories that stresses the arbitration between hierarchies and markets or emphasizes the relevance of organizational hybrids between these poles (Ménard 2014). Finally, we concentrate on the political-cultural approach but do not deal with other sociological approaches because this approach is actor-oriented and simultaneously emphasizes the underlying structure of social life. Furthermore, it is a broad theoretical approach which claims to search for mechanisms of fields in general and markets in particular (Fligstein 1996, 2001; Fligstein and McAdam 2012).

Since the paper aims to answer the question which market approach is more adequate in a critical rationalist sense, Section 2 describes the critical rationalist framework. This also implies answering the question why market theories are necessary. Section 3 deals with the new institutional economics approach and shows that it is not adequate from a critical rationalist perspective because it combines contradictory assumptions and contradicts reality. In contrast, the markets-as-institutional-arrangements approach (Vanberg 2001, 2005, 2011) and the political-cultural approach are both adequate in principle because they follow critical rationalism (Vanberg 2014) or at least a hypothetico-deductive approach in general (Fligstein 2001; Fligstein and McAdam 2012). However, it is possible that they contradict each other. Since finding out if this is the case requires a comparison of the two, we do so in Sections 4 and 5. We choose different criteria (which can be understood as elements of Weber's ideal types (Ritzer 2008)) that are important from our perspective. These criteria entail, among others, the assumption of uncertainty, the underlying hypotheses on individual behavior, the definition of power, and the understanding of its distribution. Obviously, it is possible that other comparisons would take other criteria. Section 4 outlines the markets-as-institutional-arrangements approach and Section 5 the political-cultural approach in comparison to the former. Section 6 summarizes the results and discusses some consequences of these findings. 


\section{Market theories from a critical rationalist perspective}

Market theories are relevant for analyzing existing and hypothetical markets and market orders. Because of that, the new institutional economics approach and the markets-as-institutional-arrangements approach even then refer to theories when they deal with the question how to improve existing markets (Boettke 2018). Market theories are necessary to analyze existing and hypothetical markets for several reasons: Firstly, since markets are relevant, it is important to know how they work. Secondly, to answer the question if existing or hypothetical markets are desirable, we have to know what markets can achieve and this is also a theoretical question (Boettke 2018). Thirdly, we need market theories in the context of analyzing existing and hypothetical market orders (Albert 1985, 1999; Witt 2003). Market orders should pursue certain values. Since values are usually abstract, it is necessary to substantiate them. This necessity to interpret values is a further reason to refer to market theories. Besides ethical concepts, empirical theories provide ideas how to substantiate values, e.g. the value efficiency, an evolutionary welfare criterion (Schubert 2012), ordo-liberal values like freedom of choice and equality before the law (Boettke 2018), or the reduction of power. Moreover, we should refer to market theories because market rules should support these social values and the theoretical question arises if they can do so (Boettke 2018). Answering this question also requires market theories. Obviously, we have to expect that different market theories differ regarding these points. Buchanan and Vanberg, for instance, emphasize that the neoclassical market goal 'Pareto efficiency' is not realizable from their theoretical perspective (Buchanan and Vanberg 1991). Similarly, from the perspective of a political-cultural market approach, it is never easy to make market orders support (ordo-liberal) values like freedom of choice or equality before the law. Finally, institutions, in particular market rules, can cause secondary effects, e.g., on the functioning of markets, on the behavior of individuals, or on the behavior of companies, and it is important to analyze whether these secondary effects are acceptable. Thus, we need theories that show these secondary effects to be able to evaluate them. The following Fig. 2 summarizes the reasons why we need market theories:

Critical rationalism provides a certain interpretation of (empirical) theories. Theories should solve problems and they should 'explain' facts. Explanation implies attributing single phenomena of the empirical world to general empirical laws (Hempel and Oppenheim 1948). Theories, for instance, should explain the influence of rules on the behavior of firms or individuals. Thus, according to critical rationalism, theories should search for mechanisms. At the same time, this view implies that critical rationalism takes a realist perspective. Thus, critical rationalism assumes a reality that is independent of minds (Gadenne 2008). Yet, critical rationalism emphasizes that the perception of reality is subjective and particularly influenced by theories (Popper 1968; Lavoie 1985). Since critical rationalism wants to explain facts, this view demands to test theories and that, in turn, implies formulating a prediction on the basis of a general theory and single statements and testing the prediction by observations. Yet, even if the observed results agree with the prediction, we cannot deduce that the theory is true because of the induction problem. According to 


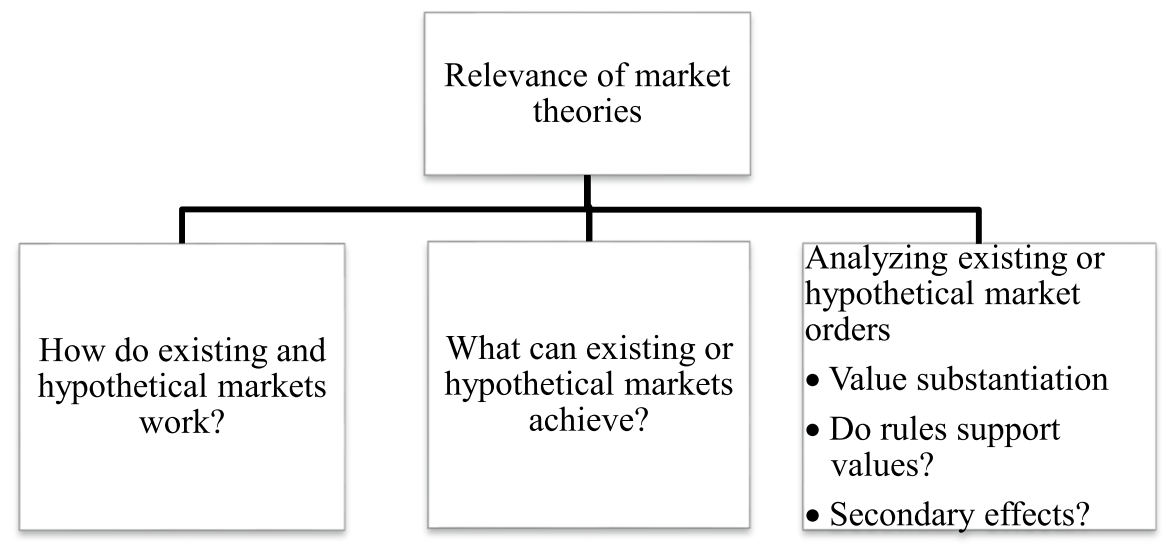

Fig. 2 Relevance of market theories

the induction problem, we cannot verify a general law proposition by a finite number of observed single phenomena (Popper 1968). Rather, we can argue that the theory is preliminarily confirmed or, in Popper's words, empirically corroborated (Popper 1968). Conversely, if the test result does not agree with the prediction, the theory is by no means finally falsified. Since it is possible that the prediction or the single statements were false (Popper 1968), we only have reasons to assume that the theory is preliminarily falsified (Gadenne 2013). ${ }^{1}$

Due to the induction problem and the problem of subjective perception, critical rationalism denies that we can achieve absolute truth. Instead, scientific knowledge is always fallible (Lakatos 1970). For that reason, critical rationalism demands that we search for contradictions (Gadenne 2006), in particular within a theory, between a theory and reality, and between theories (Stelzer 2009). According to critical rationalism, theories are not adequate when they combine contradictory assumptions because we can draw any possible conclusion from contradictory assumptions (Albert 1985). Furthermore, theories are not adequate when their assumptions contradict reality. Critical rationalism does not only subdivide theories into adequate and inadequate theories but also recommends comparing theories. The aim is to find out if they are compatible or if they contradict each other. If the latter is the case, the question arises which theory convinces more regarding its results in empirical tests and its generality (Gadenne 2006). Regarding the latter, we refer to Lakatos' "sophisticated falsificationism". Its key issue is that it values a theory not absolutely but in relation to another theory. This relative valuation is also relevant because of the strong absolute criteria of critical rationalism (Lavoie 1985). More generally, sophisticated falsificationism asks whether a certain theory $\mathrm{T}$ ' is 'better' than theory T. Lakatos specifies three characteristics to identify a comparatively 'better' theory $T^{\prime}$ : The first characteristic is that there is excess empirical content of $T^{\prime}$ in

\footnotetext{
1 We have to consider that this procedure differs from the' as-if-instrumentalism' according to Friedman. Friedman's instrumentalism does not focus on the (preliminary) empirical truth of assumptions. Rather, hypotheses are adequate if the prediction is valid (Friedman 1974; critically Musgrave 1999).
} 


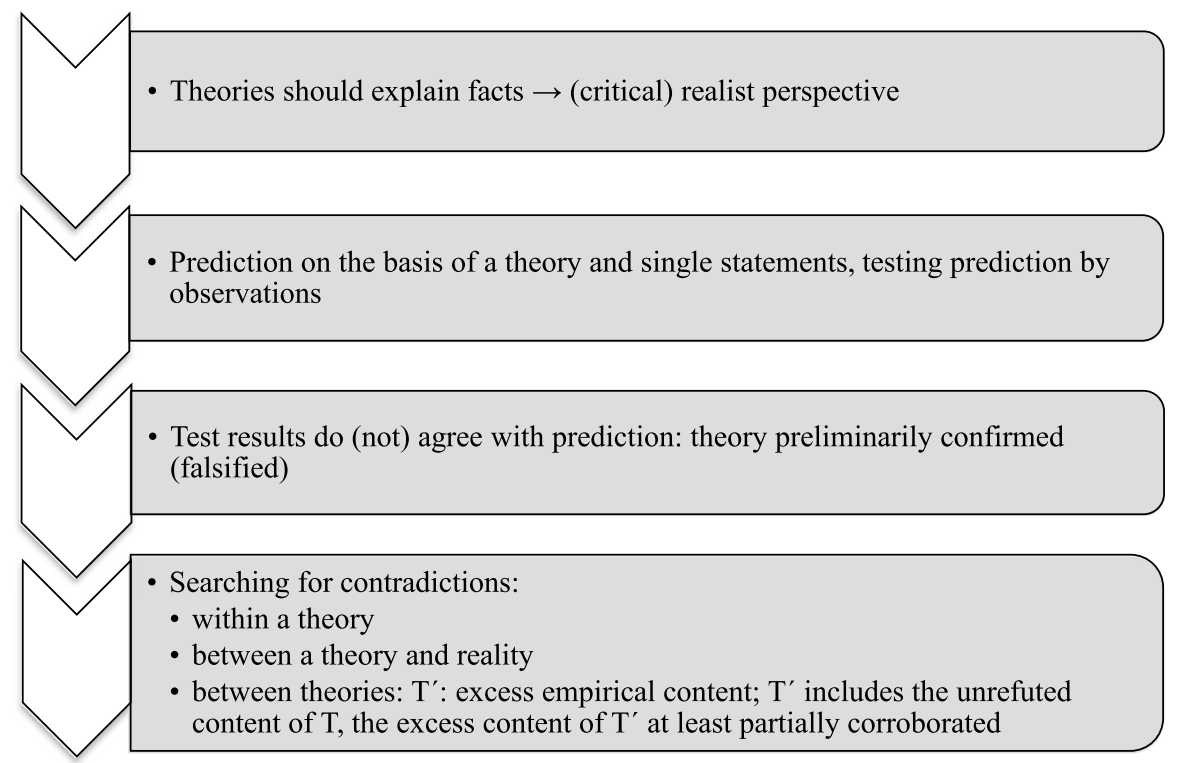

Fig. 3 Theories according to critical rationalism

comparison with $\mathrm{T}^{2}$ In other words, T' predicts facts that are improbable or even forbidden from the perspective of $\mathrm{T}$. The second characteristic is that $\mathrm{T}$ ' includes the unrefuted content of T. According to the third characteristic, the excess content of T' is at least partially corroborated (Lakatos 1970, 116). ${ }^{3}$ The following Fig. 3 summarizes the critical-rationalist understanding of theories:

\section{Markets according to the new institutional economics approach}

The new institutional economics approach is a theoretical framework that claims to differ from the neoclassical market approach by considering bounded rationality. We do not deal in detail with different parts of this approach but focus on the market interpretation that Furubotn and Richter (2005) provide and that we mentioned in Section 1 the ideal type. According to this, a market is "a social network consisting of (i) a set of actors who maintain customer relationships with each other and (ii) an order or governance structure governing the transactions

\footnotetext{
${ }^{2}$ Strictly speaking, regarding the first characteristic, Lakatos only explicitly refers to excess predictive power but not to explanatory power. As we cannot claim that prediction and explanation are structurally identical in every single case (Scheffler 1957, 293-298), we interpret the required excess empirical content that way that it includes not only excess predictive power, but also excess explanatory power.

${ }^{3}$ Economists associate Lakatos probably less with his sophisticated falsificationism but more with his characterization of research programs. As examples for such associations, see Schmidt (1982), Lavoie (1985), and Vuillemey (2014). According to Lakatos' characterization of research programs, these usually include a hard core of apparently counterfactual law propositions that are protected against criticism by a belt of auxiliary hypotheses. To be clear, we do not refer to Lakatos' characterization of research programs but refer to his sophisticated falsificationism.
} 
between individual actors. Their common goal is to lower the costs of exchange and thus to reach a higher level of individual utility. Actors have imperfect foresight and are only boundedly rational" (Furubotn and Richter 2005, 350). The important point is that markets are institutional arrangements that can increase the individual utility by reducing the costs of exchange. This interpretation of markets requires that individuals can maximize their (expected) utility under bounded rationality. We show that this optimization is only definable, however, when contradictory assumptions are combined but that this procedure is problematic from a critical rationalist perspective. We tie in with Alchian (1950) who claims that optimization can only be a meaningful action in an environment that contains certainty. We also tie in with Potts (2000) who argues (but does not show this formally) that optimization collapses if expectations are not treated as a priori given but as mere conjectural knowledge. Furthermore, we are in line with Furubotn and Richter (2005) who admit that the new institutional economics approach is based on contradictory assumptions. Yet, while all previously named authors actually do not refer to the formalism of new institutional economics, we subsequently show that optimization is impossible even within the assumptions and the formal basis of new institutional economics.

We consider the approaches of Stigler (1961) and Akerlof (1970) and, therefore, two examples for the epistemological bases of new institutional economics approaches. Both have in common that they claim on the one hand, to consider bounded rationality in the form of uncertain outcomes of individual decisions yet, on the other hand, to deduce quantitatively exact results from their models. Stigler (1961) investigates how markets function when buyers who demand a certain commodity do not know its price in advance but have to acquire information about prices. He considers that searching for information is costly and assumes that finding out a seller's price requires a certain amount of costs for the buyer. On the one hand, the more the buyer searches, i.e., the more sellers' prices he knows, the lower the expected minimum price will be of the set of known prices. On the other hand, the more the buyer searches, the higher the total search costs are. While the marginal effect of each unit of additional information on the expected minimum price decreases, the marginal costs are assumed approximately constant; at least they do not decrease. Within Stigler's approach, the optimum level of search is reached when the marginal effect on expected minimum price equals the marginal costs of search. Hence, optimization in Stigler's sense is not the same as optimization under complete information in the neoclassical market approach: optimization in the latter sense is reached when, at a given quality level, the buyer chooses the seller with the absolute minimum price on the market. In contrast, optimization in Stigler's sense does not only consider commodity prices but also information costs.

While Stigler assumes a constant quality level, Akerlof (1970) investigates the effects of commodities with uncertain quality levels on markets. He assumes that the seller of a good knows its quality level perfectly, but the buyer merely knows the frequency distribution of quality levels. Buyers maximize their expected utility and thus calculate their price limit by the average quality level. From the sellers' perspective, it is sub-optimal to sell a higher-quality good because they can only receive the equilibrium price of an average-quality good. Buyers anticipate this 
missing supply of high-quality goods in the probability distribution and adopt their price limits accordingly. The core result of Akerlof's approach is that, given asymmetric information about quality levels, a market equilibrium occurs that is characterized by a low quality level and a low price. As with Stigler's approach, optimization in the sense of Akerlof's approach is not the same as optimization under complete information in the neoclassical market approach: optimization in the latter sense is reached when the buyer chooses the commodity which helps individuals to obtain their highest-possible utility level because of its combination of price and quality. In contrast, optimization in Akerlof's sense takes the perspective that individuals know the frequency distribution of quality levels but do not know the quality level of any single offered commodity. Accordingly, also within Akerlof's approach, individuals optimize their results considering their bounded knowledge.

We argue that both Stigler's and Akerlof's assumptions lead to an indeterministic character of variety in the actors' behavioral patterns. We do not have to leave the paradigm of the new institutional economics approach to show that. Rather, we just assume that actors do not perfectly know their decision environment in advance but that they first have to acquire information about it. Indeterministic variety in the actors' behavioral patterns already follows from these assumptions, even if we accept such an approach.

Assume any decision $D$ with a given set of $m$ action alternatives $A^{D}=\left\{a_{1}^{D}, a_{2}^{D}, \ldots, a_{m}^{D}\right\}$ and a given set of $n$ possible future states of nature $S^{D}=\left\{s_{1}^{D}, s_{2}^{D}, \ldots, s_{n}^{D}\right\}$. Assume for every possible future state of nature that it has, whether known or unknown, an objective occurrence probability $p_{j}^{D}=p\left(s_{j}^{D}\right)$ for all $j=1,2, \ldots, n$. Within the examples of Stigler and Akerlof mentioned above, there are objective occurrence probabilities, too. Depending on the selected action alternative and on the actually occurred state of nature, the actor receives an outcome $x_{i j}^{D}=x\left(a_{i}^{D}, s_{j}^{D}\right)$ with the utility $u\left(x_{i j}^{D}\right)=u\left(x\left(a_{i}^{D}, s_{j}^{D}\right)\right)$.

As long as the actors know all action alternatives, all possible future states of nature, all occurrence probabilities, and all resulting outcomes in advance, they can determine the action alternative that maximizes the expected utility and we have a framework for self-contained and self-consistent models. In contrast, now assume that actors have incomplete information about these variables and, thus, are just boundedly rational as new institutional economics claims to consider. Additionally, assume that information is costly; hence, similarly to Stigler's approach, infinite search for information is suboptimal. Thus, the core decision $D$ presupposes an additional decision about what kinds of search for information and how much search for information to do. We call this presupposed decision the information decision $I_{1}$. In the sense of new institutional economics, we model the information decision the same way as we model the core decision. Hence, the information decision $I_{1}$ is a choice from a set of action alternatives $A^{I_{1}}=\left\{a_{1}^{I_{1}}, a_{2}^{I_{1}}, \ldots, a_{m}^{I_{1}}\right\}$. The set of action alternatives includes the alternative to end the search for information. Analogously to the core decision $D$, assume that $I_{1}$ is a decision under stochastic uncertainty depending on future states of nature 
$S^{I_{1}}=\left\{s_{1}^{I_{1}}, s_{2}^{I_{1}}, \ldots, s_{n}^{I_{1}}\right\}$ with occurrence probabilities $p_{j}^{I_{1}}=p\left(s_{j}^{I_{1}}\right)$ and, depending on action alternative and future state of nature, information outcomes $x_{i j}^{I_{1}}=x\left(a_{i}^{I_{1}}, s_{j}^{I_{1}}\right)$.

The reason for the presupposed information decision $I_{1}$ is that we replaced the perfect information assumption by the assumption of incomplete information. Now, of course, we could limit the incomplete information assumption thus that actors only miss information relevant for the core decision $D$ but that they have perfect knowledge about the similar variables for $I_{1}$. However, this would make the model inconsistent. Thus, we assume that the information decision $I_{1}$ itself presupposes an information decision $I_{2}$. Search for information is costly (Stigler 1961; Alchian 1969, 1972), so the core decision $D$ can hardly be optimal when the actor does unlimited search for the presupposed information decision $I_{1}$ or for the presupposed second information decision $I_{2}$. Still considering the incomplete information assumption in general, it is obvious now that $I_{2}$ presupposes a further information decision $I_{3}$. This information decision $I_{3}$ presupposes an additional information decision $I_{4}$, an information decision $I_{5}$, and infinitely so on.

According to these arguments and keeping in mind that information is costly, determining a decision alternative that maximizes expected utility is not possible any more: the actor within this model has to limit the search for information but can genuinely not do this as an optimization under constraints (Furubotn and Richter 2005; Furubotn 2009 , 2014). Instead, the actor has no better option than selecting information arbitrarily. Every trial for optimization presupposes additional information decisions again and again to infinity. Otherwise, actors would ignore utility-relevant information.

As we can see, this is a result of relaxing a central assumption of neoclassical market approaches while maintaining all other assumptions and deducing results without endangering internal consistency, just as the new institutional economics approach does. A central conclusion of the formal thoughts above is that the individual cannot optimize the decision when they should stop acquiring information Rather, individuals can only decide arbitrarily. In other words, when considering bounded rationality consistently, optimization is not possible. At first sight, according to Stigler's as well as Akerlof's approaches, individuals can maximize their utility although they only have incomplete information. However, these approaches assume given frequency distributions. This implies that they assume bounded rationality in the decision we called the core decision $D$. In contrast, they implicitly assume the opposite for what we called the information decision $I_{1}$ : frequency distributions and, thus, probability distributions, which are necessary to optimize the information decision, are given in these approaches. Hence, they explicitly assume bounded rationality for decision $D$ but implicitly assume perfect rationality for the decision $I_{1}$ for the same person. Because of this perfect rationality assumption for $I_{1}$, the further information decisions $I_{2}, I_{3}$, etc., do not play a role in Stigler's and Akerlof's approaches, even not implicitly.

The following Table 1 summarizes the key characteristics of markets according to the new institutional economics approach:

We have four objections to the new institutional economics approach. Firstly, the perfect rationality hypothesis related to the information decision contradicts reality 
Table 1 Core ideas of the new institutional economics approach

\begin{tabular}{ll}
\hline Criterion & New institutional economics approach \\
\hline Uncertainty & Genuine \\
Hypothesis on individual behavior & $\bullet$ Perfectly rational behavior (information decision) \\
& $\bullet$ Boundedly rational behavior (core decision) \\
Neoclassical theory & Not adequate \\
Neoclassical efficiency & Neither realized nor realizable \\
Market hypothesis & Markets can increase utility by reducing costs of exchange \\
\hline
\end{tabular}

(Boland 2003). Secondly, the bounded rationality hypothesis (core decision) and the perfect rationality hypothesis (information decision) are two hypotheses that contradict each other (Boland 2003; Furubotn and Richter 2005). For that reason, a crucial epistemological problem arises: The conjunction of two premises that contradict each other has the logical value 'false' and, already by reasons of propositional logic, from falsity follows anything (Albert 1985). Hence, no potential empirical observation proposition could ever contradict the hypotheses of the model. As emphasized in Section 2, contradictions between theories are problematic from a critical rationalist perspective (Stelzer 2009). Thirdly, if we accept that actors and, therefore, markets cannot maximize utility, we have to ask how actors actually behave and how markets function. According to the results above, actors who want to optimize actually decide arbitrarily. This arbitrariness means that the actors' decision behavior in general is indeterministic. As long as we attribute aggregate market results to individual decisions, as Stigler's and Akerlof's approaches do, market equilibria are not explainable by such indeterministic decision behavior. Fourthly, arbitrary decisions contradict the behavior that we can observe because behavior on markets is at least not completely arbitrary. To give an example: When managers plan to maximize the shareholder value (Fligstein 2001), we have no reasons to assume that they behave arbitrarily, even though they cannot maximize anything in the above-mentioned objective sense. Rather, we have more reasons to assume that they believe they maximize or that they act in this manner because important actors demand them to do so.

Thus, when we consider on the one hand that actors cannot maximize their utility in an objective sense but do not assume on the other hand that they act arbitrarily, we need alternative action hypotheses. One of these alternative action hypotheses could be that actors merely decide by simplified heuristics. Yet, even if they use decision heuristics based on perfect-rationality-assuming economic theories, this is different to acting in a perfectly rational manner. In contrast to the new institutional economics approach in general and in contrast to Stigler's and Akerlof's approaches in particular, such an approach requires hypotheses about how actors adopt their decision heuristics (implicitly Alchian 1950), i.e., it requires learning hypotheses (Witt 2003). Unfortunately, the new institutional economics approach usually excludes learning hypotheses by assuming the decision rule and all decision-relevant information is given a priori. Indeed, Alchian (1950) claims that comparatively less successful firms imitate action patterns of more successful firms who generate positive 
profits. Nevertheless, he applies this claim as an argument that real firms' action patterns converge to profit-maximizing action patterns as long as there is a stable environment. Hence, Alchian (1950) considers learning merely exogenously. Yet, if expectations are not treated as unambiguous data, learning and novelty have to be considered endogenously (Potts 2000). Furthermore, since the new institutional economics approach and, therefore, the idea that markets can increase actors' utility are not theoretically founded, we need interpretations of markets beyond the idea that markets are means to maximizing utility. Therefore, we analyze the marketsas-institutional-arrangements approach and the political-cultural approach. To do so, we enhance the criteria we used to characterize the new institutional economics approach (Table 1) as mentioned in Section 1. Neither of the two approaches, the markets-as-institutional-arrangements approach and the political-cultural approach, assume that markets minimize or maximize market outcomes. Rather, they interpret markets as institutional arrangements or political arenas.

\section{Markets according to the markets-as-institutional-arrangements approach}

As we mentioned in our introduction, a second strand of market approaches assumes that markets enable harmony under certain conditions although arguing that they cannot maximize or minimize anything, neither in the sense of neoclassical market approaches (Pareto efficiency) nor in the sense of the new institutional economics approach (increasing actor's utility in an objective sense). Vanberg, e.g., who presents the view that markets are institutional arrangements, does not argue that existing markets always enable harmony, but he points out that markets can enable harmony when market orders imply certain rules. Section 2 shows that answering the question whether markets can actually do so is also a theoretical one that, explicitly or implicitly, refers to market theories. Vanberg's approach considers genuine uncertainty. Thus, actors do not decide on an exhaustive set of states. Rather, they have to expect new states, not least because actors learn about and influence the future by their decisions (Buchanan and Vanberg 1991). Since individuals do not have perfect knowledge about the world, there is no reason to characterize certain decision criteria or certain decisions as perfectly rational. Rather, individuals act subjectively rationally under genuine uncertainty. This means that individuals pursue their own interests and act consistently regarding their own goals. Since they only have incomplete knowledge about the world, they can only evaluate goals and means from the perspective of their subjective knowledge. In this sense, they use decision criteria that are subjectively rational from their perspective (Vanberg 2002).

According to the markets-as-institutional-arrangements approach, not only individuals but also firms are relevant market actors. Yet, firms do not act in a literal sense. Rather, Vanberg refers to Coleman and points out that certain firms are corporate actors. According to Coleman, individuals who transfer resources to a corporate actor lose the total control over them in case of major corporate decisions. They give up parts of their rights to the collective owners and this means to the corporate actor (Coleman 1974). Vanberg follows these ideas and emphasizes the difference in 
kind between separate actions of people on markets and actions of people in organizations. The reasons are, firstly, that individuals who submit resources to an organization deny themselves the separate control over these resources and submit them to an organizational decision-making process (Vanberg 1992). Secondly, the organizational decision-making process requires rules regarding the question who is allowed to decide for the group and regarding the question how the results of the group product are distributed. Because of these organizational constraints, Vanberg points out that the members of a corporate actor pursue their own interests just like market participants. However, they act under constraints that differ from the constraints on markets. Such constraints are, for example, the rules of the decision-making process. These different rules cause the differences in kind between market settings and organizational settings (Vanberg 1992). These rules and further social mechanisms "bring about the intra-organizational coordination of individual choices and actions that make us think of organizations as corporate actors" (Vanberg 1992, 239).

One important consequence of assuming genuine uncertainty is that we cannot apply neoclassical market theory to markets (Vanberg 2001). In particular, the market goal 'neoclassical efficiency' (i.e., Pareto efficiency among all actors in the market economy) is neither realized nor realizable under genuine uncertainty because the "market economy, as an aggregation, neither maximizes nor minimizes anything" (Buchanan and Vanberg 1991, 181; Buchanan 1964). In contrast to perfectly competitive markets where institutions do not matter, markets under genuine uncertainty are institutional arrangements. Markets have an experimental character, but they do not move toward anything, and they can neither achieve neoclassical efficiency nor a tendency toward equilibrium like Hayek ${ }^{4}$ or Kirzner $^{5}$ present (Buchanan and Vanberg 1991). Rather, markets enable voluntary exchange (Buchanan 1964). Since exchange is based on the mutual agreement between actors, markets are more or less suitable for allowing individuals to act in their own interest and to realize mutual gains. To what extent markets offer these possibilities depends on the quality of the underlying rules (Vanberg 2001, 2005, 2007) but, in principle, markets enable actors to decide in their own interest and support the interests of others at the same time. The markets-as-institutional-arrangements approach refers to the coordination mechanism that Adam Smith provided. According to that, "the market game solves the problem of inducing people to care for the needs of others ... The 'social technology' by which the market game achieves this, is not to ask people to pursue other than their own interests" (Vanberg 2007, $204 \mathrm{f}$.). The underlying empirical hypothesis is that self-interested actors also take the interests of others into account because only then they can expect other actors to agree to a transaction (Buchanan and Vanberg 1991). The markets-as-institutional-arrangements approach emphasizes that it "is quite obvious that managers cannot run a business successfully for long if they do not pay due attention to the interests of their customers, their employees, their suppliers or the political community within

\footnotetext{
${ }^{4}$ Different Boettke (2018) who points out that Hayek (1978) emphasizes the relevance of coordination and institutions instead of a tendency towards equilibrium.

5 Kirzner (1992) defends a middle ground approach against proponents of a radical subjectivism like Buchanan and Vanberg.
} 
which they operate." (Vanberg 2007, 212). According to these empirical hypotheses, firstly, other actors do not contract if their interests are not adequately considered. In other words, the opportunity to deny their consent empowers actors to enforce their interests. Secondly, because of this, actors consider the interests of others in order to reach their own goals.

At the same time, actors are members of a political community and, as such, responsible for the market rules. The quality of market rules depends on the rules' suitability to align the self-interest of actors with the common interest (Vanberg 2007). Since self-interested economic activity as a constituent characteristic of a social order that coordinates interests via markets requires freedom of choice (Vanberg 2005), one important rule is to grant freedom of choice to every individual as a universal good. Yet, the markets-as-institutional-arrangements approach does not understand freedom of choice as an instrumental value. On the contrary, since markets require freedom of choice, they are adequate means to achieving the intrinsic value freedom of choice (Vanberg 2011, 2014).

The essential role of self-interested acting on markets implies that the participants in a market game have to accept enlightened profit seeking because a market order that forbids profit seeking or that demands actors to act in the interests of others against their own interest would contradict the market game (Vanberg 2007). Under genuine uncertainty, market rules cannot be objectively rational or perfect. Rather, market rules also result from evolutionary processes. They are the product of trial and error learning. In consequence, "we have the historical and contemporary record of how they work, compared to potential alternative systems of rules, that we have reason to trust in the capacity of the rules of the game of catallaxy to serve the common interest of the participants" (Vanberg 2007, 214). Communities retain rules that have proven themselves while changing or abolishing unsuitable rules (Vanberg 2005, 2007). According to the markets-as-institutional arrangements approach, rules are suitable when they support the common constitutional interests of the people concerned (Vanberg 2005, 2014). Since actors might be interested in rules that support the common constitutional interest on the one hand but provide privileges for themselves on the other hand, it is necessary to avoid privilege-seeking through adequate rules on the constitutional level (Vanberg 2005).

The markets-as-institutional-arrangements approach does not explicitly discuss the power of individuals or firms. Yet, it emphasizes that actors can deny their consent in the market game. Furthermore, political actors can influence the market rules in political and democratic processes (Vanberg 2007). Thus, the markets-as-institutionalarrangements approach implicitly assumes that, presupposing certain rules, market orders and political orders can ensure symmetrically distributed power to decide in the market game and in the political game (Vanberg 2005). The following Table 2 summarizes the core ideas of the markets-as-institutional-arrangements approach:

In contrast to the new institutional economics approach, the assumptions of the hypotheses of the markets-as-institutional-arrangements approach do not contradict reality and are not inconsistent but consistent. However, the markets-as-institutionalarrangements approach does not found its hypotheses on empirical studies. In particular, the question arises whether empirical studies would confirm that actors take the interests of other actors sufficiently into account. 
Table 2 Core ideas of the markets-as-institutional-arrangements approach

\begin{tabular}{|c|c|}
\hline Criterion & Markets-as-institutional-arrangements approach \\
\hline Uncertainty & Genuine \\
\hline Hypothesis on individual behavior & $\begin{array}{l}\text { Subjectively rational behavior } \\
\text { - Individuals pursue their own interests } \\
\text { - Individuals act consistently regarding their own goals }\end{array}$ \\
\hline Relevant actors & Individuals and firms, certain firms as corporate actors \\
\hline Neoclassical theory & Not adequate \\
\hline Neoclassical efficiency & Neither realized nor realizable \\
\hline Market hypothesis & $\begin{array}{l}\text { - Markets as institutional arrangements, more or less } \\
\text { realizing mutual gains } \\
\text { - Actors take interests of others into account to achieve } \\
\text { their own interests when market orders entail suitable } \\
\text { rules }\end{array}$ \\
\hline Market rules & $\begin{array}{l}\text { - Political community is responsible } \\
\text { - Product of an evolutionary process: cumulative, } \\
\text { experience-guided process of trial and error learning }\end{array}$ \\
\hline What are the ideas for the design of markets? & $\begin{array}{l}\text { - Rules should enable mutually beneficial cooperation } \\
\text { (beneficial to all parties involved) } \\
\text { - Markets require freedom of choice (intrinsic value) }\end{array}$ \\
\hline Power & $\begin{array}{l}\text { - Not explicit } \\
\text { - Implicit: power to deny consent and to vote }\end{array}$ \\
\hline Distribution of power & $\begin{array}{l}\text { - Not explicit } \\
\text { - Implicit: symmetric }\end{array}$ \\
\hline
\end{tabular}

\section{Markets-as-political-arenas approach in comparison to the markets-as-institutional-arrangements approach}

In contrast to the previous approaches, the third strand of market theories does not only deny that markets maximize or minimize anything but also questions harmony ideas. According to the political-cultural approach (Fligstein 1996, 2001), markets are not only institutional arrangements but also social and political arenas. Like the markets-as-institutional-arrangements approach, the markets-as-political-arenas approach considers genuine uncertainty. Thus, actors have incomplete knowledge. The political-cultural approach also argues that individuals cannot act perfectly rationally. Rather, actors try to secure their economic survival. Since their main problem is uncertainty, e.g., uncertainty regarding suppliers and customers, actors try to reduce this uncertainty (Fligstein 2001). In contrast to the markets-as-institutional-arrangements approach, the political-cultural approach emphasizes that "actors are never simply self-interested. Most of us, most of the time are motivated to affirm our membership in this or that group ... by helping to reproduce the order in question. Admittedly, sometimes we do so with an eye to preserving the narrow instrumental goods conferred by these collectives, but most of the time we are simply expressing our affiliation with the group, preserving and extending its identity, and generally honoring its existential hold on us" (Fligstein and McAdam 2012, 50). Therefore, actors' behavior does not only result from economic conditions in 
general and the price mechanism in particular but from "the structural position and opportunities actors have and their ability to recognize how they can mobilize others" (Fligstein and McAdam 2012, 49) to enhance their chances. In contrast to the markets-as-institutional-arrangements approach, the political-cultural approach does not explicitly deal with corporate actors. However, the approach also stresses the relevance of individual actions when it highlights its microfoundations (Fligstein and McAdam 2012).

The political-cultural approach also denies that neoclassical theory is adequate to explain problems that we observe in reality. In particular, the political-cultural approach doubts that markets are efficient. Just as the markets-as-institutionalarrangements approach, the political-cultural approach does not assume that markets can lead to neoclassical (Pareto) efficiency (Fligstein 2001).

The political-cultural approach also interprets markets as institutions. Consistent with the markets-as-institutional-arrangements approach, markets require rules, e.g., rules of exchange, or conceptions of control. Besides the understanding of markets as institutional arrangements, according to the political-cultural approach, markets are also social and political arenas that enable the structured exchange of goods or services. They are characterized by conflicts between their actors (Fligstein 2001). The participants in a field struggle constantly and follow the field's rules and the same holds for markets as special fields that enable structured exchange. The reason is that actors try to develop and maintain a system of domination. To reach this aim, they produce a culture of the field that entails interpretative frameworks for actors and defines social relationships. These interpretative frameworks or stories (Beckert 2013), respectively ideas (McCloskey 2016), help actors justify their actions as reasonable and interpret the actions of others (Fligstein 1996, 2001). Moreover, fields entail shared understandings about the subject of the field, about the relevant actors and their power, and about the rules (Fligstein and McAdam 2012). Obviously, there is an overlap between interpretative frameworks and shared understandings on the one hand and 'culture' which is discussed by parts of the new institutional economics approach on the other hand. Yet, the relevance of interpretative frameworks and shared understandings according to the political-cultural approach differs from the relevance of culture according to the new-institutional economics approach. While the political-cultural approach (Fligstein 2001) highlights the relevance of frameworks and shared understandings for behavior and its interpretation and justification, parts of the new institutional-economics approach emphasize the influence of culture on growth and interpret culture as constraint or incentive (Mokyr 2016; Voigt 2019; critical McCloskey 2016). While the political-cultural approach (Fligstein 2001) points out that interpretative frameworks or shared understandings first define actors' goals and the means how to achieve them, parts of the new institutional economics approach argue that culture influences the utility-seeking of actors (Mokyr 2016; Voigt 2019; critical McCloskey 2016). According to the political-cultural approach, actors try to reduce uncertainty by producing stable relations and, at the same time, stable markets. The approach differentiates between 'incumbents' and 'challengers'. Incumbent actors dominate the field. This implies that "the purposes and structure of the field are adapted to their interests, and the positions in the field are defined by their claim on the lion's share of material and status rewards. 
In addition, the rules of the field tend to favor them, and shared meanings tend to legitimate and support their privileged position" (Fligstein and McAdam 2012, 13). Incumbents have more power than challengers, who benefit less from the current arrangements. Incumbents try to reproduce their power. Therefore, they consider the actions of other incumbent firms. In contrast, challengers consider the actions of incumbents and they challenge the structure of the field when possible. Thus, power, political action, and a contentious nature are the characteristics of fields in general and of markets in particular (Fligstein and McAdam 2012).

The political-cultural approach defines power firstly as power to influence other actors. Powerful companies are able to influence other companies, but they always have to expect the resistance and claims of the dominated companies. Secondly, power entails the power to influence market rules. Thus, rules are the results of political processes and often reflect the interests of powerful groups (Bourdieu and Wacquant 1992; Bourdieu 2005; Fligstein 1996, 2001). In contrast to the marketsas-institutional-arrangements approach, implemented rules are only accepted as best-founded from the perspective of several groups or the relevant political community in special cases. Usually, powerful groups can enforce rules that are in their interest and they justify rules with interpretative frameworks. The political-cultural approach differentiates between the state, capitalists, and workers and understands these groups as collective actors. Only when the power between these groups is balanced, we can expect rules to be in the interests of several groups (Fligstein 2001).

Thus, the political-cultural approach challenges the hypothesis of the marketsas-institutional-arrangements approach that, presupposing certain market rules, self-interested actors also take the interests of others into account because only then they can expect other actors to agree to a transaction. According to the politicalcultural approach, some actors are usually more powerful than others. Less powerful actors cannot deny their agreement to a transaction without consequences (Schmiel 2020). In other words, the power distribution on markets is usually not symmetric. In consequence, less powerful actors depend on self-interested actors respecting their interests. According to the political-cultural approach, a symmetric power distribution, e.g. a worker-capitalist standoff, is only a special case. These compromise situations are possible and they can be stable because "groups maintain vigilance and promote and protect domains most important to their interests" (Fligstein 2001, 53). Yet, a stable and power-balanced situation is one possibility of many where one group or political coalition dominates others. In other words, the political-cultural approach is broader than the markets-as-institutional-arrangements approach because it includes situations of asymmetric and symmetric power distribution.

Since the political-cultural approach doubts that existing or hypothetical markets can always ensure harmony between individual interests and common interests, the argument that profit seeking of actors is in the common interest is not founded. Rather, from the political-cultural perspective, we should understand this harmony hypothesis as an interpretative framework of powerful actors that helps them justify their actions and the existing market rules (Fligstein 1996, 2001). Moreover, according to the political-cultural approach, it is by no means easy to provide a market order that ensures that actors consider the interests of others and that distributes power symmetrically. The reason for this is that powerful actors are not only able to 
influence other actors but can also enforce their interests regarding the market rules. Furthermore, a fundamental transformation of market rules can be caused by exogenous forces, e.g. by crises. This implies that even the largest firms lose their ability to reproduce themselves from period to period (Fligstein 2001). Table 3 highlights the commonalities and differences between both approaches:

Just as those of the markets-as-institutional-arrangements approach, the assumptions of the political-cultural approach do not contradict reality. Furthermore, it can explain different issues, e.g., the determinants of firm behavior in the USA in the 1970s or the influences on mergers in the USA in the 1980s (Fligstein 2001; Fligstein and McAdam 2012).

In sum, both approaches are generally adequate approaches because their assumptions do not obviously contradict reality and, additionally, neither the assumptions of the markets-as-institutional-arrangements approach nor the assumptions of the political-cultural approach are contradictory. However, there are at least two contradictions between these approaches: Firstly, while the markets-asinstitutional-arrangements approach argues that individuals act subjectively rationally, the political-cultural approach states that individuals never act simply selfinterestedly. Rather, they are interested in affirming their membership in a group. Thus, regarding this point, both approaches are only compatible when subjectively rational behavior according to the markets-as-institutional-arrangements approach also encompasses actions that result from the desire to belong to a certain group. In fact, the market-as-institutional-arrangements approach suggests this compatibility (Vanberg 2002).

Secondly, while according to the markets-as-institutional-arrangements approach, self-interested actors take the interests of other actors on markets into account (which simultaneously implies symmetric power), the political-cultural approach argues that power between (collective) actors is usually unbalanced and powerful actors can enforce their interests. This also implies implementing rules that are in these actors' interests. This challenges the idea of the markets-as-institutional-arrangements approach according to which rules result from an experience-guided trial and error process. While this implies that rules are implemented which are best-founded from the perspective of the concerned political community at that stage of the trial-and-error-process, the political-cultural approach emphasizes the relevance of power and interpretative frameworks in the process of rule implementation. From the perspective of the markets-as-institutions approach, the rules determine whether markets enable harmony between individual interests and common interest. In contrast, from the perspective of the political-cultural approach, the powerful group determines the rules and justifies them with interpretative frameworks, e.g. with the interpretation that markets enable harmony. Thus, in the light of the political-cultural approach, markets can only realize half of the idea presented by the markets-as-institutional-arrangements approach: Markets can, in general, be a means to achieving freedom of choice because self-interested economic market activity requires freedom of choice and institutions, e.g. certain market rules, are necessary to enable it. Yet, taking the political-cultural approach into account, realizing freedom of choice for all actors requires analyzing the structure of power and implementing additional mechanisms that reduce 


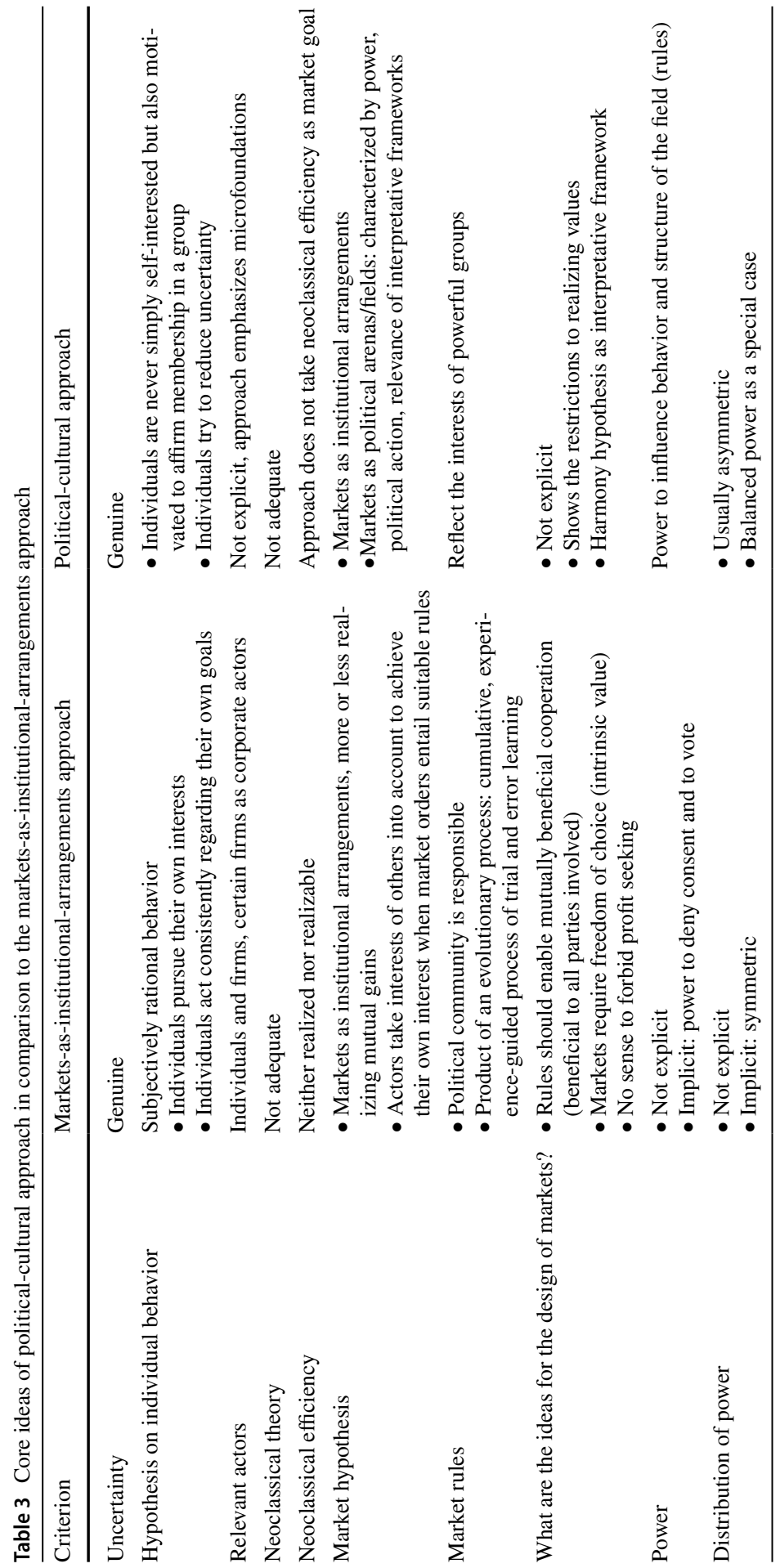


asymmetric power. Thus, institutions are necessary but not sufficient, because it is nearly impossible to implement such mechanisms when the power in a society is unbalanced.

Since both approaches are only compatible if we interpret the case of balanced power as a special case of the broader approach according to which power between collective actors is usually unbalanced, it is necessary to examine which approach is more convincing: The markets-as-institutional-arrangements approach or the political-cultural approach that includes the markets-as-institutional-arrangements approach as its special case. To answer this question, we refer to the proposal of Lakatos' sophisticated falsificationism as mentioned in Section 2.

According to Lakatos (1970), the political-cultural approach is more convincing if it has excess empirical content over the markets-as-institutional-arrangements approach. Since the political-cultural approach does not only deal with the case of balanced power but also with the case of unbalanced power, which is not subject of the markets-as-institutional-arrangements approach, this requirement is fulfilled. As the second characteristic of Lakatos' sophisticated falsificationism, the political-cultural approach also has to include the unrefuted content of the markets-as-institutional-arrangements approach. The unrefuted content of that is the hypothesis that in the case of balanced power, actors take the interests of other actors into account for their own interest. This also implies that those rules are implemented that are best-founded from the perspective of the concerned political community at this stage of the trial-and-error process. Since we interpreted this case as a special case of the political-cultural approach, the political-cultural approach includes the unrefuted content of the markets-as-institutional-arrangements approach. Thus, this requirement is also fulfilled. Thirdly, the excess content of the political-cultural approach should be at least partially corroborated. Fligstein (2001) provides an empirical study that shows the relevance of the culture of the field. The study analyzes the determinants of firm reorganizations in the USA in the 1980s. It challenges the mainstream hypothesis according to which firms were the object of reorganizations when their net worth was bigger than their stock worth. The study argues that reorganizations were only observable when powerful actors considered them as reasonable. In other words, firm reorganizations depended on a certain perspective of the corporation, specifically, on a shareholder value view. This perspective had the character of an interpretative framework that helped actors justify their actions as reasonable and interpret the actions of others. More generally, the study supports the idea that "market relations are embedded in social relations" (Fligstein 2001, 168). Obviously, acting in the manner of the shareholder value perspective does not imply taking the interests of other actors sufficiently into account (Stout 2012). Rather, Fligstein emphasizes that the shareholder value approach is in the interest of shareholders and investment bankers (Fligstein 2001). Thus, the dominance of the shareholder value approach reflects that shareholders and investment bankers, as the dominant group, are able to enforce market rules which are in their interest. In sum, from our perspective, we have good arguments to accept the political-cultural approach as the (preliminarily) more convincing approach and to interpret the markets-asinstitutional-arrangements approach as its special case. 


\section{Conclusion and discussion}

Market theories are relevant because markets are relevant. Thus, we have to know firstly, how existing and hypothetical markets work; secondly, what they can achieve, and thirdly, how we can improve the market order. Dealing with these points requires market theories: Market theories provide ideas how to substantiate social values. Furthermore, we need market theories to assess whether existing or hypothetical market rules support certain social values. Finally, market theories show the secondary effects of market rules. Because of these points, market theories are vital. Since, from an evolutionary perspective, market theories should consider genuine uncertainty, we analyzed the new institutional economics approach, the markets-as-institutionalarrangements approach, and the political-cultural approach. According to the new institutional economics approach, markets are social networks that enable boundedly rational actors to increase their utility (Furubotn and Richter 2005). In contrast, the markets-as-institutional-arrangements approach argues that although markets cannot maximize or minimize market outcomes, they can enable harmony when suitable rules are implemented (Vanberg 2005). The political-cultural approach understands markets not only as institutional arrangements but also as social and political arenas with conflicts between their relevant actors (Fligstein 1996, 2001).

Obviously, the existence of different theories raises the question which theory we should consider. Since choosing a market theory should not be ad hoc but reasonable, we have to analyze these 'ideal types' (Ritzer 2008) of market theories with regard to their adequacy. This procedure is in opposition to Chang's 'anything goes'-attitude that "different approaches to economics can actually benefit a lot from learning from each other, making our understanding of the economic world richer." (Chang 2014, 115). Analyzing theories regarding their adequacy requires a measure to evaluate theories. The present paper refers to a critical-rationalist framework. This methodological view evaluates, i.a., whether theories contradict themselves, whether they contradict reality, or whether they contradict other theories. To evaluate theories that contradict each other, we additionally refer to Lakatos' "sophisticated falsificationism" (Lakatos 1970, 116).

Since the assumptions of the new institutional economics approach contradict reality and contradict each other, this approach is not adequate in a critical-rationalist sense. In consequence, the idea that markets can increase actors' utility in an objective sense is not theoretically founded. In contrast, the markets-as-institutional-arrangements approach and the political-cultural approach fulfill critical-rationalist requirements. They neither obviously contradict reality nor combine contradictory assumptions. Thus, the question arises if these theories are compatible or if they contradict each other. The present paper deals with this question, which has not been answered in the literature so far. It compares both approaches regarding several criteria and comes to the result that they contradict each other in at least two points. Firstly, both approaches are only compatible when subjectively rational behavior according to the markets-as-institutional-arrangements approach also includes those actions which, according to the political-cultural approach, express that actors want to affirm their membership of a certain group. Secondly, both approaches are only compatible if we 
interpret the standard case of balanced power according to the markets-as-institutionalarrangements approach as a special case of the broader political-cultural approach. This means assuming power as usually unbalanced and only exceptionally balanced. Thus, the hypothesis that actors take the interests of other actors into account is only reasonable in the case of balanced power.

Since the markets-as-institutional-arrangements approach and the political-cultural approach contradict each other or, more precisely, are only compatible in certain interpretations, we ask if we have reasons to prefer the political-cultural approach. According to Lakatos' sophisticated falsificationism, this is the case because the political-cultural approach has excess empirical content, predicts facts that are improbable from the perspective of the markets-as-institutional-arrangements approach and is at least partially corroborated (Lakatos 1970). Thus, we refer to the political-cultural approach and interpret the markets-as-institutional-arrangements approach as its special case.

Obviously, the markets-as-institutional-arrangements approach and the political-cultural approach have different consequences regarding the explanation of existing markets and market orders and also regarding the question how to improve them. According to the markets-as-institutional-arrangements approach, markets (at least hypothetical markets equipped with certain market rules) can enable harmony because self-interested actors as a constitutive element of markets consider the interests of others. From the perspective of the political-cultural approach, such a mechanism does not work when power between (collective) actors is unbalanced. When managers should pay attention to "the interests of their customers, their employees, their suppliers or the political community within which they operate", we cannot expect that they will actually do so because they want to "run a business successfully for long" (Vanberg 2007, 212). From the perspective of the political-cultural approach, the only idea of the markets-as-institutional-arrangements approach that holds is that markets can generally support freedom of choice. They can do so because self-interested economic activity as a constituent characteristic of a social order that coordinates interests via markets requires freedom of choice (Vanberg 2005, 2011). If markets should additionally guarantee that actors considered legitimate interests of others, e.g., if managers should pay attention to "the interests of their customers, their employees, their suppliers or the political community within which they operate" (Vanberg 2007, 212), societies would have to discuss and reflect such values (Levy and Peart 2017) and market orders would have to define those values accordingly.

The political-cultural approach also has different consequences for analyzing and improving the market order. As we mentioned above, a first consequence follows for the interpretations of values. If, e.g., the social order aims at reducing power, we have to consider that the power interpretation of the political-cultural approach differs from that of the markets-as-institutional-arrangements approach. The first interprets power as the power to influence other actors and the rules. In contrast, the markets-as-institutional-arrangements approach implicitly understands power as the power to deny consent and to vote. Obviously, the latter interpretation is only adequate in the special case of symmetric power. Secondly, market theories should answer the question if existing or hypothetical rules support social values, especially freedom of choice or additional legitimate interests of other actors. Since from the perspective of the political-cultural approach, powerful actors are able to influence other actors and their freedom of choice, realizing freedom of choice requires analyzing the structure of power 
and implementing additional mechanisms that reduce asymmetric power. Moreover, according to the political-cultural approach, we cannot expect rules to be implemented that enable freedom of choice or the protection of legitimate interests of other actors. The reason is that powerful actors can also enforce their interests regarding the market rules. In consequence, we have to expect that powerful actors are able to prevent a mechanism that shall reduce their power. Therefore, taking a political-cultural view implies not only focusing on desirable social values on markets like freedom of choice or other legitimate interests and on market rules that support these values. Rather, we also have to consider that power is necessary to implement such market rules. Rules and other institutions are necessary but not sufficient because, above all, their implementation needs power. We only have reasons to believe that market orders really entail rules that support freedom of choice and induce actors to take the legitimate interests of other actors into account when these institutions are in the interest of powerful actors or when power is symmetrically distributed.

In sum: since markets are relevant, market theories are relevant. Since market theories considerably differ in their hypotheses about how markets work, what they can achieve, how to substantiate social values, which rules support social values, and what secondary effects result from rules, the analysis of market theories is also relevant. We agree with Levy and Peart (2017) that a rule-governed discussion of values and policy goals is relevant. Our findings show that a rulegoverned discussion of desirable social values and policy goals requires considering market theories. Only then do societies know which social values markets can achieve, how to substantiate values in a theory-based manner, which social values could be supported by rules, and which secondary effects have to be accepted.

Funding Open Access funding enabled and organized by Projekt DEAL.

\section{Declarations}

Conflict of interest The authors declare that they have no conflict of interest.

Open Access This article is licensed under a Creative Commons Attribution 4.0 International License, which permits use, sharing, adaptation, distribution and reproduction in any medium or format, as long as you give appropriate credit to the original author(s) and the source, provide a link to the Creative Commons licence, and indicate if changes were made. The images or other third party material in this article are included in the article's Creative Commons licence, unless indicated otherwise in a credit line to the material. If material is not included in the article's Creative Commons licence and your intended use is not permitted by statutory regulation or exceeds the permitted use, you will need to obtain permission directly from the copyright holder. To view a copy of this licence, visit http://creativecommons.org/licen ses/by/4.0/.

\section{References}

Akerlof GA (1970) The market for "lemons": quality uncertainty and the market mechanism. Quart J Econ 84(3):488-500

Alchian AA (1950) Uncertainty, evolution, and economic theory. J Polit Econ 58(3):211-221

Alchian AA (1969) Information costs, pricing, and resource unemployment. Econ Inq 7(2):109-128 
Alchian AA (1972) Production, information costs, and economic organization. Am Econ Rev 62(5):777-795

Albert H (1985) Treatise on critical reason. Princeton University Press, Princeton

Albert H (1999) Between social science, religion and politics - essays in critical rationalism. Rodopi, Amsterdam/Atlanta

Beckert $\mathbf{J}$ (1996) What is sociological about economic sociology? Uncertainty and the embeddedness of economic action. Theory Soc 25(6):803-840

Beckert J (2013) Imagined Futures: fictional expectations in the economy. Theory Soc 42(3):219-240

Boettke PJ (2012) Living economics. Yesterday, today, and tomorrow. The Independent Institute, Oakland

Boettke PJ (2018) FA Hayek: Economics, political economy and social philosophy. Springer, London

Boettke PJ, Candela R (2017) Price Theory as prophylactic against popular fallacies. J Inst Econ 13(3):725-752

Boland LA (2003) The foundations of economic method. A Popperian perspective, 2nd edn. Routledge, London

Bourdieu P (2005) principles of an economic anthropology. In: Smelser NJ, Swedberg R (eds) The handbook of economic sociology, 2nd edn. Princeton University Press, Princeton, pp 75-89

Bourdieu P, Wacquant LJD (1992) The purpose of reflexive sociology. In: Bourdieu P, Wacquant LJD (eds) An invitation to reflexive sociology. Polity Press, Cambridge, pp 61-216

Buchanan JM (1964) What should economists do? South Econ J 30(3):213-222

Buchanan JM, Vanberg VJ (1991) The market as a creative process. Econ Philos 7(2):167-186

Chang H-J (2011) Institutions and economic development: theory, policy and history. J Inst Econ 7(4):473-498

Chang H-J (2014) Economics: the user's guide. Bloomsbury Press, New York

Coleman JS (1974) Power and the structure of society. W. W. Norton \& Company, New York

Dopfer K (2012) The origins of meso economics - Schumpeter's legacy and beyond. J Evol Econ 22(1):133-160

Dopfer K, Potts J (2008) The new evolutionary economics. Edward Elgar Publishing, Cheltenham

Dopfer K, Foster J, Potts J (2004) Micro-meso-macro. J Evol Econ 14(3):263-279

Dosi G, Marengo L, Fagiolo G (2005) Learning in the evolutionary environments. In: Dopfer K (ed) The evolutionary foundations of economics. Cambridge University Press, Cambridge, pp 255-338

Fligstein N (1996) Markets as politics: a political-cultural approach to market institutions. Am Sociol Rev 61(4):656-673

Fligstein N (2001) The architecture of markets: an economic sociology of twenty-first-century capitalist societies. Princeton University Press, Princeton

Fligstein N, McAdam D (2012) A theory of fields. University Press, Oxford

Friedman M (1974) The methodology of positive economics. In: Friedman M (ed) Essays in positive economics, 8th edn. University of Chicago Press, Chicago, pp 3-43

Furubotn EG (2009) Heuristics, the non-maximizing firm and efficient allocation. Metroeconomica 60(1):1-23

Furubotn EG (2014) Entrepreneurial judgment, decision procedure and the inevitable emergence of the non-optimizing firm in a capitalist economy. Metroeconomica 65(4):548-570

Furubotn EG, Richter R (2005) Institutions and economic theory: the contribution of the new institutional economics, 2nd edn. The University of Michigan Press, Michigan

Gadenne V (2006) Methodological rules, rationality, and truth. In: Cheyne C (ed) Rationality and reality: conversations with Alan Musgrave. Springer, Dordrecht, pp 97-107

Gadenne V (2008) The construction of realism. Constructivist Foundations 3(3):153-159

Gadenne V (2013) External validity and the new inductivism in experimental economics. Rationality, Markets and Morals 4:1-19

Hayek FA (1978) Competition as a discovery procedure. In: Hayek FA (ed) New studies in philosophy, politics, economics and the history of ideas. Routledge, London, pp 179-190

Hempel CG, Oppenheim P (1948) Studies in the logic of explanation. Philosophy of Science 15(2):135-175

Kirzner IM (1992) The meaning of market process: essays in the development of modern Austrian economics. Routledge, London

Kay J, King M (2020) Radical uncertainty. Bridge Street Press, London 
Lakatos I (1970) Falsification and the methodology of scientific research programmes. In: Lakatos I, Musgrave A (eds) Criticism and the growth of knowledge. Cambridge University Press, Cambridge, pp 91-196

Lavoie D (1985) Tacit knowledge and the revolution in the philosophy of science. National economic planning: what is left? Ballinger Publishing Company, Cambridge, pp 247-265

Levy D, Peart S (2017) Escape from democracy. Cambridge University Press, New York

McCloskey DN (2016) Max U versus humanomics: a critique of neo-institutionalism. J Inst Econ 12(1):1-27

Ménard C (2014) Embedding organizational arrangements: towards a general model. J Inst Econ 10(4):567-589

Mokyr JA (2016) A culture of growth: the origins of the modern economy. Princeton University Press, Princeton

Musgrave A (1999) Essays on realism and rationalism. Rodopi, Amsterdam

OECD (2020) Why open markets matter. https://www.oecd.org/trade/understanding-the-global-tradingsystem/why-open-markets-matter/. Accessed 22 Jan 2020

Popper KR (1968) The logic of scientific discovery, 2nd edn. Hutchinson \& Co., London

Potts J (2000) The new evolutionary microeconomics. Edward Elgar, Cheltenham

Ritzer G (2008) Sociological theory, 7th edn. McGraw-Hill, New York

Scheffler I (1957) Explanation, prediction, and abstraction. Br J Philos Sci 7(28):293-309

Schmidt R (1982) Methodology and finance. Theor Decis 14(4):391-413

Schmiel U (2020) Economic analysis of tax law from a sustainability perspective. Fla Tax Rev 23(2):597-624

Schubert C (2012) Is novelty always a good thing? Towards an evolutionary welfare economics. J Evol Econ 22(3):585-619

Stelzer H (2009) Popper and communitarianism: Justification and criticism of moral standards. In: Parusniková Z, Cohen RS (eds) Rethinking Popper, Boston studies in the philosophy of science, vol 272. Springer, Dordrecht, pp 273-286

Stigler GJ (1961) The economics of information. J Polit Econ 69(3):213-225

Stout LA (2012) The shareholder value myth: how putting shareholders first harms investors, corporations, and the public. Berrett-Koehler Publishers, San Francisco

Vanberg V (1992) Organizations as constitutional systems. Const Polit Econ 3(2):223-253

Vanberg V (2001) Markets and the law. In: Smelser N, Baltes P (eds) International encyclopedia of the social and behavioral sciences, vol 14. Elsevier, Amsterdam, pp 9221-9227

Vanberg V (2002) Rational choice vs. program-based behavior. Ration Soc 14(7):7-54

Vanberg V (2005) Market and state: the perspective of constitutional political economy. J Inst Econ 1(1):23-49

Vanberg V (2007) Corporate social responsibility and the 'game of catallaxy': The perspective of constitutional economics. Const Polit Econ 18(2):199-222

Vanberg V (2011) Consumer welfare, total welfare and economic freedom - on the normative foundation of competition policy. In: Drexl J (ed) Competition policy and the economic approach. Edward Elgar, Cheltenham, pp 44-71

Vanberg V (2014) Evolving preferences and welfare economics: The perspective of constitutional political economy. Jahrbücher für Nationalökonomie und Statistik 234(2-3):328-349

Voigt S (2019) Institutional economics. Cambridge Books, Cambridge

Vuillemey G (2014) Epistemological foundations for the assessment of risks in banking and finance. J Econ Methodol 21(2):125-138

Witt U (2003) Economic policy making in evolutionary perspective. J Evol Econ 13(2):77-94

Witt U (2008) What is specific about evolutionary economics? J Evol Econ 18(5):547-575

Witt U (2009) Novelty and the bounds of unknowledge in economics. J. Econ. Methodol. 16(4):361-375

Publisher's note Springer Nature remains neutral with regard to jurisdictional claims in published maps and institutional affiliations. 